\title{
Photoperiodic control of the intensity of diapause and diapause development in the bean bug, Riptortus clavatus (Heteroptera: Alydidae)
}

\author{
Keis NAKAMURA* and Hideharu NUMATA
}

Department of Bio- and Geosciences, Graduate School of Science, Osaka City University, Osaka 558-8585, Japan

Key words. Heteroptera, Riptortus clavatus, adult diapause, diapause intensity, diapause development, photoperiod

\begin{abstract}
Adult diapause in Riptortus clavatus (Thunberg) was induced by short-day photoperiods, and the critical daylength for its induction was $13.5 \mathrm{~h}$. When insects were reared from eggs under diapause-inducing photoperiods near the critical daylength, the duration of diapause was shorter than when reared under the shorter daylengths. Adults terminated diapause under long-day photoperiods earlier when they had been raised under a near-critical photoperiod than under shorter daylengths; this indicated that the initial intensity of diapause was dependent on the length of the inducing photoperiod. Not only the photoperiods experienced during preimaginal development but also the value of the long-day photoperiods experienced after adult emergence affected the time of onset of oviposition. When the photophase was shortened, either abruptly or gradually after adult emergence, the duration of diapause was prolonged. Diapause was long when induced by shorter daylengths than the near-critical photoperiod. Different photoperiods have thus different quantitative effects on both the initial intensity of diapause and the rate of diapause development.
\end{abstract}

\section{INTRODUCTION}

Photoperiod is one of the most important factors regulating the duration of diapause in insects (Tauber et al., 1986; Danks, 1987). The duration of diapause is usually determined by the initial intensity of diapause and the rate of diapause development. The intensity of diapause has been estimated by transferring diapausing insects to diapause terminating photoperiods. For example, in insects that terminate diapause under long-day photoperiods, the period between the transfer to long days and the termination of diapause was used as an index of the intensity (e.g., McLeod \& Beck, 1963; Hodek, 1971; Tauber \& Tauber, 1972; see Hodek, 1983 for review). On the other hand, the rate of diapause development has been measured by keeping diapause insects under various photoperiods (e.g., Tauber \& Tauber, 1973, 1976; Butterfield, 1976). Photoperiod can affect the initial intensity of diapause, the rate of diapause development, or both. Tauber \& Tauber $(1972,1973)$ showed that in Chrysopa carnea, photoperiod within the range of short-day photoperiod affects both the intensity of diapause and the rate of diapause development.

Photoperiodic responses can be classified as either qualitative or quantitative (see Zaslavski, 1988 for review): In the qualitative photoperiodic response, two alternative conditions are provoked, for example, diapause is induced and averted under photoperiods short and long relative to a threshold, respectively. In the quantitative photoperiodic response, the absolute duration of daylength regulates a gradual change in responses such as developmental rate, fecundity or preoviposition period. Adult diapause in $C$. carnea is induced by a qualitative response under stationary photoperiods (Tauber \&
Tauber, 1970, 1972). After the induction, however, the diapause is maintained by a quantitative photoperiodic response (Tauber \& Tauber, 1973). Quantitative photoperiodic responses have been found in several other species (Zaslavski, 1988; Hardie, 1990; Kimura, 1990; Spieth \& Sauer, 1991).

Adult bean bugs, Riptorfus clavatus (Thunberg), enter diapause and overwinter. Diapause is induced by shortday photoperiods below a critical daylength of about 13.5 $\mathrm{h}$ in a population from Kyoto, Japan (Numata \& Hidaka, 1982; Kobayashi \& Numata, 1995). Numata \& Hidaka (1983) showed that diapause in $R$. clavatus was averted when photoperiod was increased within the range of short-day photoperiods (from $8 \mathrm{~L}: 16 \mathrm{D}$ or $10 \mathrm{~L}: 14 \mathrm{D}$ to 13L : 11D). The intensity of diapause in $R$. clavatus was lower when insects were reared as nymphs under 13L : 11D than when kept under shorter daylengths, showing a quantitative difference in the intensity (Numata \& Hidaka, 1983). However, it is not clear whether such a quantitative difference is found also at long-day photoperiods. It is also unknown whether short-day photoperiods affect the rate of diapause development. Furthermore, it is unclear how the initial intensity of diapause and the rate of diapause development determine the duration of diapause. In the present study, we examined (1) the duration of diapause in insects kept continuously under different short-day photoperiods, (2) the initial intensity of diapause by transferring newly-emerged adults from various short-day to long-day photoperiods, and (3) the effect of abrupt and gradual decreases in photoperiod on the rate of diapause development after the induction of diapause.

\footnotetext{
* Present address: Department of Chemistry, Faculty of Science, Okayama University of Science, Okayama 700-0005, Japan; e-mail:nakamura@chem.ous.ac.jp.
} 


\section{MATERIAL AND METHODS}

Adults of Riptortus clavatus were collected in Kyoto, Japan $\left(35^{\circ} 00^{\prime} \mathrm{N}, 135^{\circ} 45^{\prime} \mathrm{E}\right)$ in 1992,1993 and 1996 and were kept in male-female pairs in plastic cups $(200 \mathrm{ml})$ and fed seeds of soybean and water. Eggs laid by the adults were placed under various photoperiods at $25 \pm 1{ }^{\circ} \mathrm{C}$ within $24 \mathrm{~h}$ of oviposition. Nymphs were reared on seeds of soybean and water containing ascorbic acid (Kamano, 1991), in plastic containers $(15 \mathrm{~cm}$ diameter, $9 \mathrm{~cm}$ depth) at an initial density of about 30 insects per container. Newly emerged adults were reared similarly to those collected in the field. The mortality and oviposition of these adults were recorded daily.

We did three experiments. First, insects were reared under constant photoperiods from the egg stage. Then, the insects reared under various short-day photoperiods were transferred to one of the two long-day photoperiods (14L : 10D or 16L : 8D) at adult emergence, and maintained until they oviposited in order to determine the initial intensity of diapause. In the third set of experiments, insects were reared from eggs under a photoperiod of $13 \mathrm{~L}: 11 \mathrm{D}$, and then this photoperiod was decreased after adult emergence to determine the rate of diapause development. Transfers between photoperiods were carried out 0 (within 24 h), 15 or 30 days after adult emergence. In addition to various stationary photoperiods, a gradual shortening of the photophase was used. This was achieved by using a time switch controlled by a computer; the photophase was shortened from 13 to $10 \mathrm{~h}$ by 1.5 or 2 min every day. Results in each experimental series were obtained with the same insect samples in a same year.

\section{RESULTS}

The results for insects reared from egg to adult under seven constant photoperiods are given in Fig. 1. Under 14L : 10D, 15L : 9D or 16L : 8D, almost all adult females oviposited shortly after emergence. There was no significant variation in the preoviposition period at these photoperiods ( $\mathrm{P}>0.05$ by Kruskal-Wallis test). Under $10 \mathrm{~L}$ : 14D, 11L : 13D or 12L : 12D, most females did not lay eggs during the 120-day experimental period. Under 13L : $11 \mathrm{D}$, no female oviposited within 70 days of emergence, but more than $50 \%$ started ovipositing in the subsequent 50 days. Thus, the duration of diapause is much shorter under $13 \mathrm{~L}: 11 \mathrm{D}$ than under shorter photoperiods.

Insects were also reared under various diapauseinducing short-day photoperiods and then transferred to either of the two long-day photoperiods (14L : 10D and $16 \mathrm{~L}: 8 \mathrm{D})$ at adult emergence, and maintained there until they oviposited (Fig. 2). Under these long-day photoperiods, there were significant differences in the preoviposition periods of the females reared at the four photoperiods ( $\mathrm{P}<0.05$, Kruskal-Wallis test). Under $14 \mathrm{~L}: 10 \mathrm{D}$, the females raised under 13L : 11D started oviposition significantly earlier than those raised under 12L : 12D, 11L : 13D or $10 \mathrm{~L}: 14 \mathrm{D}[\mathrm{P}<0.05$, nonparametric multiple comparisons (Zar, 1996: 227)]. Under 16L : 8D the preoviposition period was significantly shorter in females reared under $13 \mathrm{~L}: 11 \mathrm{D}$ or $12 \mathrm{~L}: 12 \mathrm{D}$ than in those reared under $11 \mathrm{~L}: 13 \mathrm{D}(\mathrm{P}<0.05)$. Adults raised under $12 \mathrm{~L}: 12 \mathrm{D}$ started ovipositing earlier under $16 \mathrm{~L}: 8 \mathrm{D}$ than under $14 \mathrm{~L}$ : 10D $(\mathrm{P}<0.05$, Mann-Whitney U-test $)$.

When transferred from $10 \mathrm{~L}: 14 \mathrm{D}$ to $13 \mathrm{~L}: 11 \mathrm{D}$ at adult emergence, some females started oviposition shortly after adult emergence (Fig. 3). When transferred from 13L :

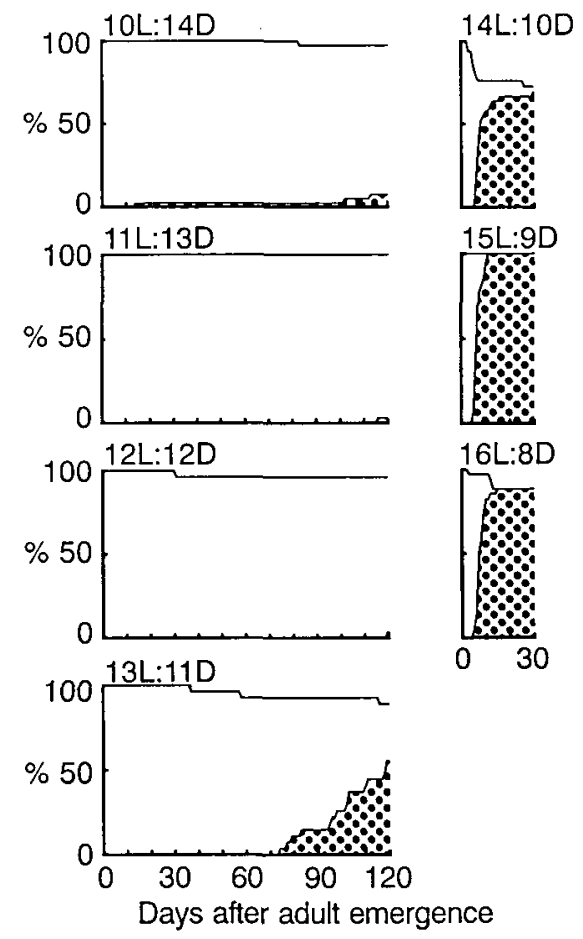

Fig. 1. Time of onset of oviposition in Riptortus clavatus kept at constant photoperiods at $25^{\circ} \mathrm{C}$. (Dotted areas: cumulative percentage of females ovipositing, $n=24-41$.)

$11 \mathrm{D}$ to $10 \mathrm{~L}: 14 \mathrm{D}$, no female started oviposition during the 120-day experimental period.

In another set of experiments, photoperiod was decreased for 15 days after adult emergence. A small proportion of females started oviposition more than 200 days after adult emergence (Fig. 4). More females started oviposition when the transfer to another photoperiod was made 30 days after adult emergence. When the photophase was shortened by 2 or $1.5 \mathrm{~min}$ per day from 13 to $10 \mathrm{~h}$, no females started oviposition before 120 days after adult emergence. The preoviposition period was not significantly different between the two photoperiodic re-

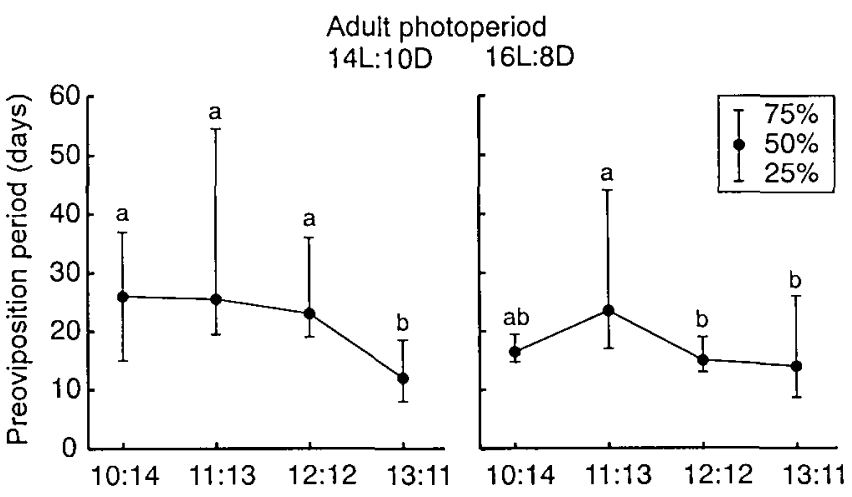

Fig. 2. Effect of different short-day photoperiods experienced in the nymphal period on the termination of diapause under long-day photoperiods in the adult stage at $25^{\circ} \mathrm{C}$ in Riptortus clavatus. $\mathrm{n}=20-32$. There is no significant difference in the preoviposition period at either photoperiod where the values have the same letter $[P>0.05$, nonparametric multiple comparisons (Zar, 1996: 227)]. 

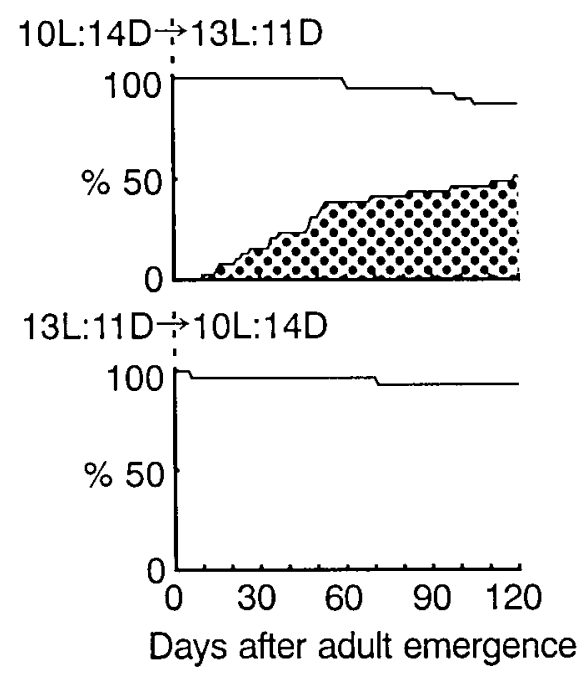

Fig. 3. Time of onset of oviposition after transfer between two short-day photoperiods (13L : $11 \mathrm{D}$ and $10 \mathrm{~L}: 14 \mathrm{D})$ at $25^{\circ} \mathrm{C}$ in Riptortus clavatus. Transfer between photoperiods was carried out at adult emergence. (Shaded areas: cumulative percentage of females ovipositing, $n=30-39$.)

gimes ( $\mathrm{P}>0.05$, Mann-Whitney U-test), although the proportion of females that started ovipositing was significantly higher in the experimental series where the daily decrease in the photophase was $2 \mathrm{~min}(\mathrm{P}<0.05$, Fisher's exact probability test).

\section{DISCUSSION}

Riptortus clavatus is a long-day insect; reproduction proceeds under long-day photoperiods, whereas short-day conditions induce diapause. The critical daylength for the induction of diapause was between 13 and $14 \mathrm{~h}$, as previously reported (Numata \& Hidaka, 1982; Kobayashi \& Numata, 1995). Several other long-day insects or mites show differences in the duration of diapause within the range of short-day photoperiod (Danks, 1987). Two contrasting types of response to photoperiod were reported. Duration of diapause was greater under photoperiods closer to the critical daylength in Manduca sexta under constant photoperiods (Bell et al., 1975). In contrast, the duration of diapause was shorter in C. carnea (Tauber \& Tauber, 1972) and Neoseiulus fallacis (Rock et al., 1971) when it was induced at photoperiods closer to the critical daylength. Riptortus clavatus belongs to the latter group. Numata \& Hidakit 1 1983) examined the intensity of diapause in $R$. clavalus by transferring insects from various short-day photoperiods to a long-day photoperiod (14L : 10D) at adult emergence. The insects kept under 13L : $11 \mathrm{D}$ as nymphs started oviposition earlier than those kept under shorter photoperiods. Numata \& Hidaka (1983) concluded that diapause is less intense when the nymphs developed under photoperiods close to the critical level within the range of diapause-inducing photoperiods. The present results confirm that diapause in $R$. clavatus has a relatively low intensity under photoperiods near the critical level for the induction of diapause. In this regard its response is similar to $C$. carnea (Tauber \& Tauber, 1972) and Ostrinia mubilalis (McLeod \& Beck, 1963). Further-
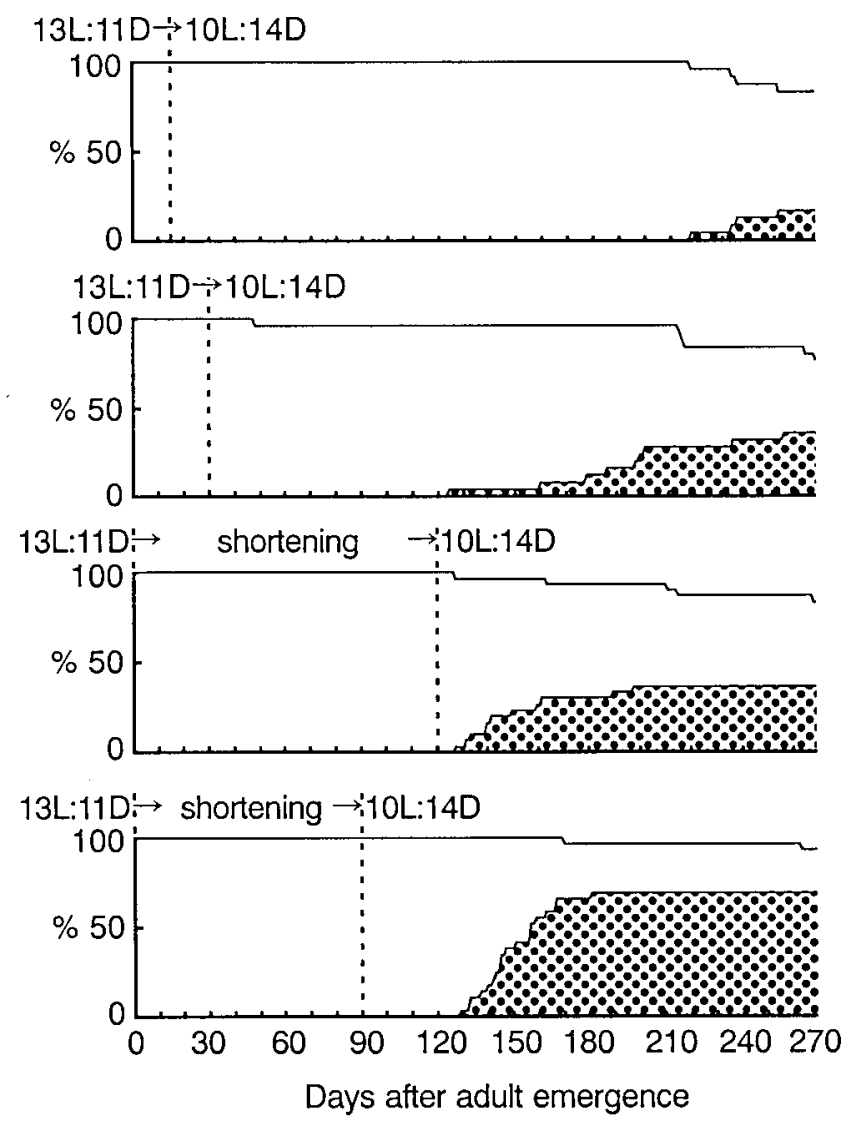

Fig. 4. Time of onset of oviposition after decrease in photophase from $13 \mathrm{~h}$ to $10 \mathrm{~h}$ in Riptortus clavatus at $25^{\circ} \mathrm{C}$. Abrupt decrease in photophase was carried out 15 or 30 days after adult emergence. Gradual shortening was started at adult emergence; the photophase was shortened from 13 to $10 \mathrm{~h}$ by 1.5 or 2 min every day. (Shaded areas: cumulative percentage of females ovipositing, $n=24-29$.)

more, two long-day photoperiods had different effects on the onset of oviposition. Many authors have used the period between the transfer to a long-day photoperiod and the termination of diapause as an index for diapause intensity in long-day insects (e.g., McLeod \& Beck, 1963; Hodek, 1971; Tauber \& Tauber, 1972). However, our results indicate that the index of diapause intensity obtained by this method depends also on the value of long-day photoperiod used for terminating diapause.

When transferred from $10 \mathrm{~L}: 14 \mathrm{D}$ to $13 \mathrm{~L}: 11 \mathrm{D}$ at adult emergence, some females quickly started ovipositing, even though both photoperiods are diapause-inducing (Fig. 3). This indicates that insects can respond to an actual increase in photoperiod (not merely to a long-day photoperiod), as Numata \& Hidaka (1983) have already reported. Similar responses are known in other insects and mites (e.g. Rasumova, 1969; Tauber \& Tauber, 1970; Eichhorn 1977). When transferred from 13L : 11D to 10L : 14D at adult emergence, no female oviposited within 120 days. This transfer prolonged the duration of diapause bccause half of the females began to lay eggs before 120 days when kept under 13L : 11D, both as nymphs and adults. 
As mentioned above, Numata \& Hidaka (1983) showed that there was a difference in the intensity of diapause when reared under different short-day photoperiods. In the earlier paper, however, it was unclear whether different short-day photoperiods affect the rate of diapause development. When transferred abruptly 15 or 30 days after adult emergence, the duration of diapause was also prolonged. Diapause development probably proceeds more slowly under 10L : 14D than under 13L : 11D. However, another interpretation is possible. In some species diapause is less intense in early adult life, and more intense later (Hodek, 1983). We do not know whether this occurs in this species; the abrupt transfer to $10 \mathrm{~L}: 14 \mathrm{D}$ might affect the intensification of diapause rather than the rate of diapause development.

In some insects, critical daylengths for the induction of diapause change during the course of diapause development (Danks, 1987). For example, the critical daylength for diapause induction in another bug, Pyrrhocoris apterus, is $1 \mathrm{~h}$ shorter than that for the termination of diapause (Saunders, 1983). If such a change in the critical daylength occurs after the induction of diapause, it could modify the control of diapause duration. In $R$. clavatus, photoperiodic response curves for the re-induction of diapause are different when insects were transferred from two different short-day photoperiods to a long-day photoperiod at adult emergence and then transferred to various photoperiods after 60 days (Numata, 1990). It shows that the critical photoperiod is not stable in this species. Therefore, the present results may be explained by a change in the critical daylength during diapause. Further experiments are necessary to resolve this point.

When the photophase was shortened gradually from 13 to $10 \mathrm{~h}$, to avoid an abrupt change in photoperiod, the duration of diapause was prolonged. These results favour the hypothesis that the photoperiodic transfer affects the rate of diapause development. However, the preoviposition period did not vary whether the daily decrease in the photophase was $1.5 \mathrm{~min}$ or $2 \mathrm{~min}$, although we had expected that the earlier start of the shorter photoperiod would prolong the duration of diapause. Furthermore, more females laid eggs when the photophase was shortened by 2 min per day although there was no variation in the preoviposition period (Fig. 4). The reason for these differences is unclear.

Photoperiod plays an important role in determining the duration of diapause in $R$. clavatus by affecting both the initial intensity of diapause and the rate of diapause development. In nature, diapause induced early in autumn is probably not intense because it is induced under photoperiods near the critical photoperiod, but is prolonged by the slower diapause development induced by the shortening daylengths of autumn. This response would prevent insects from terminating diapause before the onset of winter.

\section{REFFERENCES}

Bell R.A., Rasul C.G. \& Joscilm F.G. 1975: Photoperiodic induction of the pupal diapause in the tobacco hornworm, Manduca sexta. J. Insect Physiol. 21: 1471-1480.
BUtTERFIELD J. 1976: Effect of photoperiod on a winter and on a summer diapause in two species of cranefly (Tipulidae). J. Insect Physiol. 22: 1443-1446.

Danks H.V. 1987: Insect Dormancy: An Ecological Perspective. Biological Survey of Canada, Ottawa, $439 \mathrm{pp}$.

EıcIIIIORN O. 1977: Autökologische Untersuchungen an Populationen der gemeinen Kiefern-Buschhornblattwespe Diprion pini (L.). Z. Angew. Entomol. 84: 264-282.

HARDIE J. 1990: The photoperiodic counter, quantitative daylength effects and scotophase timing in the vetch aphid Megoura viciae. J. Insect Physiol. 36: 939-949.

HODEK I. 197I: Termination of adult diapause in Pyrrhocoris apterus (Heteroptera: Pyrrhocoridae) in the field. Entomol. Exp. Appl. 14: 212-222.

HODEK I. 1983: Role of environmental factors and endogenous mechanisms in the seasonality of reproduction in insects diapausing as adults. In Brown V.K. \& Hodek I. (ed.): Diapause and Life Cycle Strategies in Insects. W. Junk, The Hague, pp. 9-33.

K^M^no S. 1991: Riptortus clavatus (Thunberg) (Bean bug). In Yushima K. et al. (ed.): Rearing Methods of Insects. Japan Plant Protection Association, Tokyo, pp. 46-49 (in Japanese).

KimurA M.T. 1990: Quantitative response to photoperiod during reproductive diapause in the Drosophila auraria species complex. J. Insect Physiol. 36: 147-152.

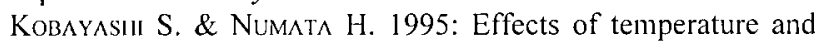
photoperiod on the induction of diapause and the determination of body coloration in the bean bug, Riptortus clavatus. Zool. Sci. 12: 343-348.

MCLeod D.G.R. \& BECK S.D. 1963: Photoperiodic termination of diapause in an insect. Biol. Bull. 124: 84-96.

Numıta H. 1990: Photoperiodic induction of the first and the second diapause in the bean bug, Riptortus clavatus: a photoperiodic history effect. J. Comp. Physiol. (A) 167: 167-171.

NumAt八 H. \& HidAkA T. 1982: Photoperiodic control of adult diapause in the bean bug, Riptortus clavatus Thunberg (Heteroptera: Coreidae) 1. Reversible induction and termination of diapause. Appl. Entomol. Zool. 17: 530-538.

Numata H. \& Hidnka T. 1983: Photoperiodic control of adult diapause in the bean bug, Riptortus clavatus Thunberg (Heteroptera: Coreidae) II. Termination of diapause induced under different photoperiods. Appl. Entomol. Zool. 18: 439-441.

Rasumova A.P. 1969: Experimental analysis of phenology of the European red mite Panonychus ulmi Koch (Acarina, Tetranychidae). Zool. Zh. 48: 212-217 (in Russian, English abstr.).

Rock G.C., YEARGAN D.R. \& RABB R.L. 1971: Diapause in the phytoseiid mite, Neoseiulus (T.) fallacis. J. Insect Physiol. 17: 1651-1659.

SAUNDERS A.S. 1983: A diapause induction-termination asymmetry in the photoperiodic responses of the linden bug, Pyrrhocoris apterus and an effect of near-critical photoperiods on development. J. Insect Physiol. 29: 399-405.

SI'ILTII H.R. \& S SULR K.P. 1991: Quantitative measurement of photoperiods and its significance for the induction of diapause in Pieris brassicae (Lepidoptera, Pieridae). J. Insect Physiol. 37: $231-238$.

TAuber M.J. \& TAublr C.A. 1970: Photoperiodic induction and termination of diapause in an insect: Response to changing day lengths. Science (Washington) 167: 170.

TAuber M.J. \& TAuber C.A. 1972: Geographic variation in critical photoperiod and in diapause intensity of Chrysopa carnea (Neuroptera). J. Insect Physiol. 18: 25-29.

TAuber M.J. \& TAuber C.A. 1973: Quantitative response to daylength during diapause in insects. Nature (London) 244: 296-297. 
Tauber M.J. \& TAuber C.A. 1976: Environmental control of univoltinism and its evolution in an insect species. Can. $J$. Zool. 54: 260-265.

Tauber M.J., Tauber C.A. \& Masaki S. 1986: Seasonal Adaptations of Insects. Oxford University Press, New York, 411 pp.
Z^R J.H. 1996: Biostatistical Analysis. 3rd ed. Prentice-Hall, Upper Saddle River, $718 \mathrm{pp}$.

ZnsLıvSKI V.A. 1988: Insect Development, Photoperiodic and Temperature Control. Springer, Berlin, New York, 187 pp.

Received January 20, 1999; accepted November 1, 1999 